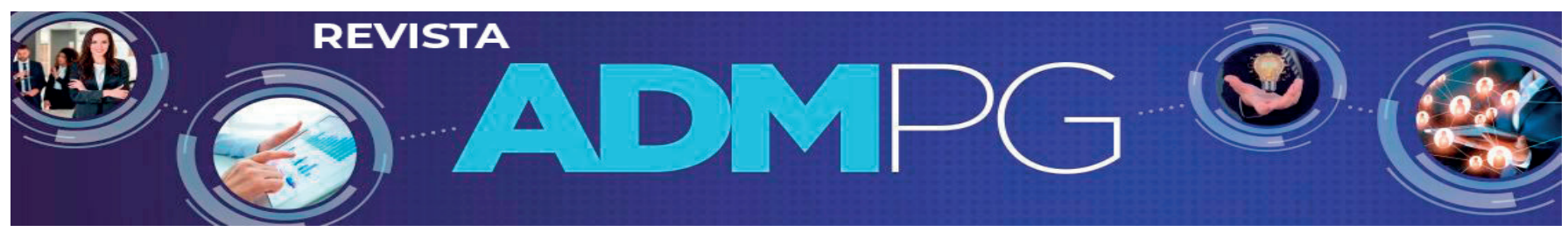

DOI: 10.5212/Admpg.v.10.14761.005

ISSN: 1983-7089

\title{
JORNADA PROFISSIONAL E ACADÊMICA: O CONFLITO E O IMPACTO NA QUALIDADE DE VIDA NO TRABALHO
}

\author{
PROFESSIONAL AND ACADEMIC JOURNEY: CONFLICT AND IMPACT ON QUALITY OF WORKING LIFE
}

VIAJE PROFESIONAL Y ACADÉMICO: CONFLICTO E IMPACTO EN LA CALIDAD DE LA VIDA LABORAL

\author{
Fernanda Camargo Vieira Pinto \\ Luana Gonsalez da Silveira ${ }^{2}$ \\ Marina Akemi Teoi Chaves ${ }^{3}$ \\ Fabricio Stocker ${ }^{4}$
}

\section{RESUMO}

O presente estudo pretende analisar os impactos da conciliação da jornada de trabalho com a jornada acadêmica na qualidade de vida no trabalho em estudantes universitários, relação pouco explorada em estudos acadêmicos. Para tanto, foi realizada uma Survey e obtidas 226 respostas válidas de indivíduos que conciliaram trabalho e estudo durante sua jornada de trabalho/estudos. A pesquisa busca identificar a percepção dos indivíduos, com relação a carga horária trabalhada, benefícios oferecidos, atividades voltadas ao bem-estar, tempo de deslocamento para o trabalho e faculdade, sintomas de cansaço, estresse ou depressão já apresentados dentre outras abordagens pertinentes ao tema. Com base nas respostas obtidas, identificamos que cerca de $70 \%$ dos respondentes acreditam que o fato de conciliar trabalho e estudo prejudicava o desempenho na faculdade e indicação de diversos sintomas apresentados durante o período de trabalho e estudo conjunto. Além disso, foram realizados testes ANOVA para testar a correlação entre a qualidade de vida no trabalho com os fatores relacionados a dupla jornada levada pelos participantes da pesquisa. Com este trabalho buscamos contribuir para o direcionamento de novos estudos que avaliem o desgaste físico e emocional apresentado por estudantes que conciliam estudo e trabalho e os impactos que a dupla jornada tem na QVT.

Palavras Chave: Estudantes Universitários. Qualidade de Vida no Trabalho. Síndrome de Burnout. Sofrimento no Trabalho.

\begin{abstract}
The present study aims to analyze the impacts of the conciliation of the working journey with the academic journey in the quality of working life in university students, a relationship not deepened explored in academic studies. For that, a Survey was conducted and 226 valid answers were obtained from individuals who, at some point, had to reconcile work and study. The research sought to identify individuals' perceptions, regarding the hours worked, benefits offered, welfare activities, travel time to work and college, symptoms of fatigue, stress or depression, among other pertinent approaches to the theme. Based on the answers obtained, we identified that about $70 \%$ of the respondents believe that reconciling work and study impaired college performance, and an indication of various symptoms presented during the study and work period. In addition, ANOVA tests were performed in the sample, but it was not possible to state in a significant way that there is a relationship of QWL with the factors related to the double journey taken by the participants of the research. With this work, we seek to contribute to new studies that evaluate the physical and emotional exhaustion presented by students that reconcile study and work and the impacts that the double journey has on QWL.
\end{abstract}

Keywords: University Students. Quality of Working Life. Burnout Syndrome. Suffering at Work.

\section{RESUMEN}

El presente estudio tiene como objetivo analizar los impactos de la conciliación del camino de trabajo con el camino académico en la calidad de la vida laboral en los estudiantes universitarios, una relación no profundizada explorada en estudios académicos. Para ello, se llevó a cabo una Encuesta y se obtuvieron 226 respuestas válidas de personas que, en algún momento, tuvieron que conciliar el trabajo y el estudio. La investigación buscó identificar las percepciones de las personas, con respecto a las horas trabajadas, los beneficios ofrecidos, las actividades de

\footnotetext{
${ }^{1}$ Fundação Escola de Comércio àlvares Penteado - FECAP - Brasil - e-mail: fernanda.cvpl7@gmail.com

${ }^{2}$ Fundação Escola de Comércio àlvares Penteado - FECAP - Brasil - e-mail: luana3gima@hotmail.com

${ }^{3}$ Fundação Escola de Comércio àlvares Penteado - FECAP - Brasil - e-mail: teoiakemi@gmail.com

${ }^{4}$ Universidade de São Paulo - FEA/USP - Brasil - e-mail: fabriciostocker@usp.br
}

Revista ADMPG, Ponta Grossa, v. 10, e2014761, p. 1- 13, 2020. 
bienestar, el tiempo de viaje al trabajo y la universidad, los síntomas de fatiga, estrés o depresión, entre otros enfoques pertinentes para el yo. Sobre la base de las respuestas obtenidas, identificamos que alrededor del $70 \%$ de los encuestados creen que la conciliación del trabajo y el estudio deterioró el rendimiento universitario, y una indicación de varios síntomas presentados durante el período de estudio y trabajo. Además, se realizaron pruebas de ANOVA en la muestra, pero no fue posible afirmar de manera significativa que existe una relación de QWL con los factores relacionados con el doble viaje realizado por los participantes de la investigación. Con este trabajo, buscamos contribuir a nuevos estudios que evalúen el agotamiento físico y emocional presentado por los estudiantes que concilian el estudio y el trabajo y los impactos que el doble viaje tiene en QWL.

Palabras Clave: Estudiantes Universitarios. Calidad de vida laboral. Síndrome de Burnout. Sufrimiento en el trabajo.

\section{INTRODUÇÃ̃o}

Por meio do desenvolvimento das atividades profissionais, o trabalhador busca atingir seu sustento, a satisfação de suas necessidades e, consequentemente, se transforma como pessoa e como profissional. Partindo da premissa de que as relações de trabalho ocorrem dentro das organizações, e os indivíduos que as compõem estão em constante transformação, obtém-se uma grande variedade de temas para pesquisa (Kurogi, 2008).

Um tema que tem despertado maior interesse é a Qualidade de Vida no Trabalho (QVT), que vem gerando debates noâmbito da saúde e do trabalho apresentando como resultantes transformações organizacionais (Marras, 2010; Boas \& Morin, 2017; Lírio, Severo \& Guimarães, 2018). A QVT refere-se ao grau de satisfação com o trabalho, possibilidade de crescimento na empresa, reconhecimento, salário adequado, benefícios de acordo com o esperado, relacionamentos interpessoais dentro e fora da equipe, ambiente físico e a liberdade de tomar decisões e poder participar ativamente das atividades (Limongi-França, 2008).

Com o aumento da expectativa de vida e o consequente aumento do tempo de vida no trabalho, a QVT tornou-se uma necessidade e premissa importante da gestão das organizações (Boas \& Morin, 2017). Muito dessa importância advém do fato de que, quando não observada a QVT, o funcionário pode acabar por desenvolver diversas doenças psicossomáticas como depressão, ansiedade, Síndrome de Burnout, dentre outras.

A cobrança contínua por produtividade e rápida entrega faz com que o indivíduo tenha que lidar diariamente com um alto nível de stress no trabalho. Somado a isso, cresceu a demanda por funcionários mais qualificados e que estejam continuamente buscando aprimorar sua educação profissional (Santos \& Borges, 2018).

Diante desse contexto, considerando como base a QVT e suas consequências na vida do indivíduo, o presente trabalho abordará a relação e os possíveis impactos de uma jornada dividida entre trabalho e estudos, e como a organização pode ajudar a amenizar os efeitos negativos.

Conforme abordado acima, este trabalho posiciona-se no campo dos estudos da Qualidade de Vida no Trabalho (QVT) e busca analisar este fenômeno no cotidiano de estudantes universitários que tenham a jornada dupla e a necessidade de conciliação entre a carreira profissional e a jornada acadêmica. O estudo tem como objetivo analisar os impactos da conciliação das vidas profissional e acadêmica na qualidade de vida no trabalho em estudantes universitários $\mathrm{O}$ problema de pesquisa fundamenta-se na seguinte questão: Como conciliar a vida profissional e acadêmica impacta na qualidade de vida no trabalho de estudantes universitários?

\section{REFERENCIAL TEÓRICO}

\subsection{Qualidade de Vida no Trabalho}

Conforme descrito por Limongi-França (1997), a Qualidade de Vida no Trabalho (QVT) é o conjunto das ações que uma empresa pode realizar envolvendo a implantação de melhorias e inovações gerenciais e tecnológicas no ambiente de trabalho. A QVT está relacionada com níveis de satisfação e bem-estar que o trabalhador usufrui no exercício de suas funções. Esses níveis de satisfação ou felicidade refletem no desempenho e nos resultados da empresa, sendo assim a QVT tornou-se indispensável para gerenciar as ações que visam à satisfação e melhorias para o funcionário nas instituições (Limongi-França, LimongiFrança \& Barbosa, 2016). 
Os primeiros estudos da Teoria da Administração, que abordam o tema, tratam da condição humana no ambiente organizacional. Através dos estudos de Hawthorne, experiência realizada em 1927 por Elton Mayo, busca-se enfatizar o lado humano e social das organizações, considera a fábrica como uma instituição social, com necessidades e hierarquias de classes (Marras, 2010). Dejours, Dessors e Destriaux (1993) definiu condições de trabalho como as pressões físicas, mecânicas, químicas e biológicas do posto de trabalho. $\mathrm{O}$ autor descreve que as pressões vindas do trabalho refletem direta ou indiretamente na estrutura física dos trabalhadores, pois podem ocasionar desgaste, envelhecimento e doenças somáticas.

Maslow, com o Modelo da Hierarquia de Necessidades, que explica a motivação por meio de necessidades humanas organizadas em níveis de importância, coloca em pauta as necessidades do indivíduo, seja de segurança, de associação, de prestígio e de autorrealização, gerando influência nas interpretações sobre motivação, necessidades e incentivos. (Marras, 2010)

Ainda que estudiosos tenham tratado do tema anteriormente, alguns autores indicam que a expressão Qualidade de Vida no Trabalho (QVT) passou a ser utilizada partir dos anos 70, nos Estados Unidos, para ações de apoio ao empregado e práticas relacionadas à atividade física e educação alimentar (Zanelli, 2010). Todavia, alguns autores sinalizam que a origem do movimento de QVT passou a ser observada a partir da década de 50, com o surgimento da abordagem sociotécnica, abordagem organizacional que reconhece a interação entre pessoas e a tecnologia nas empresas.

A consolidação da expressão veio ocorrer somente na década de 60, tendo à frente cientistas sociais, líderes sindicais, empresários e governantes em busca de melhores formas de organizar o trabalho a fim de minimizar os impactos negativos do emprego na saúde e no bem-estar geral dos trabalhadores, o que reforça a utilização do termo uma década depois como resultante de uma série de estudos e necessidades dos trabalhadores e empresas (Limongi-França, Limongi-França \& Barbosa, 2016).

De acordo com Limongi-França (1997, p.80), “a construção da qualidade de vida no trabalho ocorre a partir do momento em que se olha a empresa e as pessoas como um todo, o que chamamos de enfoque biopsicossocial". O posicionamento biopsicossocial, conceito amplo que visa estudar a causa ou o progresso de doenças utilizando-se de fatores biológicos, fatores psicológicos e fatores sociais, representando assim "o fator diferencial para a realização de diagnóstico, campanhas, criação de serviços e implantação de projetos voltados para a preservação e desenvolvimento das pessoas, durante o trabalho na empresa" (Limongi-França, 1997, p.80).

Questões sobre o ser humano no trabalho são sempre múltiplas e complexas no âmbito das pessoas, dos departamentos, dos órgãos fiscalizadores e da própria comunidade. Sendo assim, surge uma necessidade de gerenciar com efetividade a QVT, constituindo um desafio político e organizacional (Lírio, Severo \& Guimarães, 2018). Entende-se por desafio político a necessidadedecriar regras, metas, buscar especialistas qualificados no tema, equipes ou departamentos que sejam direcionados para tratar dessas questões e até mesmo a necessidade de definir um orçamento prévio que deverá ser destinado à QVT, para que as práticas e incentivos sejam eficazes para os indivíduos da instituição.

Levando em consideração a complexidade da aplicação de ações voltadas à QVT, faz-se necessário abordar as variáveis dos trabalhadores envolvidos por etapas. Assim sendo, ações iniciais possíveis de serem desenvolvidas no ambiente organizacional para auxiliar na manutenção da saúde dos trabalhadores podem ser classificadas em ações de recuperação, proteção e promoção da saúde (Coutinho, Maximiano \& Limongi- França, 2010). Sendo as ações de recuperação da saúde as desenvolvidas com pessoas já doentes, auxiliando na recuperação física e mental. As ações e proteção visando evitar a exposição a agentes nocivos e, por fim, as ações de promoção de saúde, que possuem carácter mais abrangente e ultrapassam a preocupação com a prevenção de doenças. (Limongi-França, 1997).

Diante da necessidade que uma organização possui de gerenciar e mensurar a qualidade de vida de seus funcionários no trabalho antes e depois das ações que deseja implementar em QVT, surge a Gestão de Qualidade de Vida no Trabalho (GQVT), resumido em um conjunto de escolhas de bem-estar que busca o equilíbrio biológico, psicológico, social e organizacional (BPSO), por meio do vínculo dos funcionários com o trabalho (Marras, 2010).

As quatro divisões de BPSO tratam dos seguintes enfoques - Biológica: hábitos saudáveis, conforme

Revista ADMPG, Ponta Grossa, v. 10, e2014761, p. 1- 13, 2020. 
ação inicial em QVT já tratada anteriormente; Psicológica: autoestima e reconhecimento, valorização do funcionário e de suas atividades na empresa; Social: consumo e educação, programas com incentivos a cursos de especialização, graduação e afins; Organizacional: ergonomia e clima, preocupação com o relacionamento dos funcionários na empresa (Marras, 2010).

Entretanto, ainda que existam vários estudos que tratam do tema e que diversas organizações levam a QVT com seriedade, muitas vezes a QVT nas empresas tem sofrido perda de credibilidade por causa da aparente superficialidade e por ser usada por gestores como apenas mais uma forma de adiar soluções e mudanças efetivas nas condições de trabalho que são necessárias na organização, soluções paliativas são de curto prazo quando tratamos de QVT, sendo necessário todo um planejamento e acompanhamento (Kanikadan \& Limongi-França, 2007). Todavia, ainda que se observe essa lacuna entre o discurso e prática, as preocupações com a Gestão da QVT vêm ganhando grande expressão e forma em âmbito mundial, assim como no ambiente organizacional brasileiro (Marras, 2010; Milhome \& Rowe, 2016).

\subsection{SíndRome de Burnout}

Literalmente, o termo Burnout quer dizer "queimar até o final". É usado metaforicamente para definir aquilo que chegou ao seu fim, com danos em seu desempenho físico ou mental (Trigo, Teng \& Hallak, 2007). Isso indica que a síndrome é desencadeada quando se esgotam todos os recursos de energia usados pelo profissional contra o sofrimento causado pelo trabalho, assim sendo não há mais condições físicas e mentais para desenvolver as suas atividades (Pereira, 2002).

Grande parte dos autores (Guimarães \& Cardoso, 2004; Boas \& Morin, 2017) acredita que o termo Burnout foi utilizado pela primeira vez, no ambiente laboral, por Herbert Freudenberger, médico psicanalista. Após constatar, na década de 70, que muitos de seus funcionários começaram a apresentar sintomas como desgaste emocional e desmotivação, geralmente acompanhados de sintomas físicos e psíquicos, utilizou a expressão para nomear uma síndrome que já possuía diagnóstico descrito pela literatura.

Em síntese, a Síndrome de Burnout "é um tipo de resposta prolongada a estressores emocionais e int er pess oa is crônicos no trabalho” (Castro, 2013, p. 50). Entende-se que, quando o indivíduo é exposto a situações estressantes no trabalho, ele se torna mais propenso a desenvolver Burnout. Dessa forma, ações organizacionais relativas à QVT podem diminuir a incidência dessas e outras doenças psicossomáticas.

Profissionais que ao mesmo tempo estão em fase de aperfeiçoamento e desenvolvimento educacional, como o caso de estudantes, podem estar vulneráveis a uma maior influência dos fatores que causam a Síndrome de Burnout e os demais agravantes da falta de qualidade de vida no trabalho, o que vem sendo abordado em estudos recentes neste contexto, como por exemplo a pesquisa de Santos e Borges (2018), que analisaram a relação entre a QVT e a satisfação com a vida em alunos de graduação em uma Universidade Federal e observaram que, à medida que a QVT cresce a satisfação dos alunos com a vida também cresce.

\section{METODOLOGIA}

A pesquisa é descritiva, ou seja, buscará caracterizar o comportamento do fenômeno e, a partir dela, será possível conseguir informações a respeito das características do problema estudado (Collins \& Hussey, 2005), a abordagem é quantitativa, cuja intenção é explicar as variáveis consideradas em forma de valores numéricos, representando todos os dados ou frequências obtidas.

A forma de coleta de dados utilizada foi a Survey, procedimento para coleta de dados primários a partir de indivíduos, quando o projeto de pesquisa envolve coleta de informações de uma amostra (Hair, 2005). Utilizou-se a Escala de Likert, que procura mensurar atitudes ou opiniões, tradicionalmente usando entre cinco e sete pontos para avaliar a intensidade com que alguém concorda ou discorda de um conjunto de afirmações e, para cada ponto na escala, desenvolve-se um rótulo para expressar a intensidade dos sentimentos do respondente (Hair, 2005).

Foi utilizada a amostra por conveniência, que é um tipo de amostra não probabilística, aquela que envolve escolhas de amostragem por parte do pesquisador (Mattar, 1996). A amostra por conveniência é empregada quando entrevistados são recrutados pelos pesquisadores, contatando unidades convenientes da amostragem. Para obter as informações necessárias para a avaliação desta pesquisa, foram coletadas as respostas de pessoas que já conciliaram as vidas acadêmica e profissional.

Revista ADMPG, Ponta Grossa, v. 10, e2014761, p. 1- 13, 2020. 


\subsection{Etapas da Pesquisa}

O questionário foi elaborado com uma pergunta inicial para excluir respondentes que não faziam parte do público alvo da pesquisa, ou seja, aqueles que nunca conciliaram vidas acadêmica e profissional. Em seguida, perguntas como gênero, idade, relacionamento afetivo, renda, entre outras, foram aplicadas com a intenção de caracterizar a amostra. As perguntas da segunda parte do questionário tinham como objetivo identificar qual era o segmento da empresa e cargo que os respondentes exerciam, bem como carga horária semanal e transporte utilizado para locomoção a trabalho e faculdade, por exemplo. Já a última parte da pesquisa foi dedicada a coletar dados sobre a percepção dos respondentes sobre a dupla jornada que exercem ou já exerceram e sobre a sua QVT.

Inicialmente foi realizado um pré-teste, do dia 20 de agosto até 21 de setembro de 2018, com 40 respondentes. Aintenção era verificar se o formato das perguntas estava adequado ao objetivo do trabalho, se as questões estavam claras, se seria necessário realizar algum ajuste no modelo de respostas fixado ou se seria válido disponibilizar a resposta com campo aberto. Para isso, o teste foi aplicado em formandos e formados conhecidos, para obterfeedbacks mais detalhados e reformular as questões quando necessário. Tanto no pré-teste, quanto na versão final, para facilitar a coleta de dados e obter um maior número de respondentes, foi utilizada a plataforma online Formulários Google (Google Forms). O pré-teste foi importante, pois após a aplicação, alguns ajustes ainda foram realizados no instrumento de pesquisa, buscando garantir uma maior assertividade na aplicação final.

Para buscar respondentes com aderência ao perfil desejado, o instrumento final, validado após o préteste, foi divulgado em redes sociais, como WhatsApp e Facebook, no período de 27 de setembro a 10 de outubro de 2018. No total, foram coletadas 262 respostas, sendo que 226 foram válidas por configurarem respondentes que conciliaram vida profissional e acadêmica em algum momento da vida.

\section{APRESENTAÇÃO DOS RESULTADOS}

\subsection{Estatísticas Descritivas}

A amostra se constituiu de 226 indivíduos que cursam ou que já concluíram a graduação, pós-graduação, mestrado ou doutorado trabalhando simultaneamente, sendo que $143(63,3 \%)$ são do gênero feminino e 83 (36,7\%) são do gênero masculino. Com relação à idade, a maior parcela dos respondentes, 132 (58,4\%), está na faixa etária de 21 a 25 anos, 94 (36,3\%) têm mais de 26 anos, 12 respondentes (5,3\%) têm 20 anos ou menos.

A maior parte da amostra, 128 (56,6\%) indivíduos, corresponde a estudantes que estão cursando o ensino superior. 59 respondentes (26,1\%) possuem ensino superior completo e 39 (17,3\%) cursam ou concluíram pós-graduação, mestrado ou doutorado. Referente ao ano de formação, 92 (40,7\%) dos respondentes afirmaram ter concluído a formação acadêmica e 134 (59,3\%) tem previsão de conclusão em 2018 ou até 2023.

Com relação à renda, tomando como base o salário mínimo vigente no ano de 2018 (R \$954,00), foram observados respondentes com rendas variadas, mas aproximadamente $89,38 \%$ possui renda superior a um salário mínimo. Foi perguntado também como faziam o uso da mesma, sendo que os respondentes puderam escolher mais de uma opção. Dessa forma, obteve-se um total de 43 respondentes que afirmaram utilizar a renda para pagar a faculdade, 89 para pagar despesas da família, 38 para pagar despesas da casa e 149 para pagar despesas pessoais, sendo que existem intersecções nas respostas.

A grande maioria dos respondentes estava em início de carreira quando teve que conciliar a dupla jornada, configurando $50 \%$ de estagiários, $12,39 \%$ de auxiliares, $15,49 \%$ de assistentes e $11,06 \%$ de analistas juniores. O restante configura-se em analistas pleno e sênior, coordenador e acima e proprietário.

Um número expressivo dos respondentes, 44,69\%, atuavam no setor financeiro (26,55\%) ou na indústria $(18,4 \%)$ durante o período em que tiveram que conciliar trabalho e estudo. Os demais respondentes se concentraram no comércio (11,50\%), serviços (11,95\%) e tecnologia $(11,50 \%)$, além de setores menos representativos.

Para checar se a quantidade de horas trabalhadas durante a semana tem impactos na qualidade de vida dos estudantes que tiveram que conciliar trabalho e estudo, inicialmente, foi recebida a sinalização

Revista ADMPG, Ponta Grossa, v. 10, e2014761, p. 1- 13, 2020. 
média dessas horas pelos respondentes. Com 12,83\% abaixo de 21 horas, 26,11\% entre 21 e 30 horas, $27 \%$ entre 31 e 40 horas, $22,57 \%$ de 41 a 44 horas e 11,50\% acima de 44 horas semanais (gráfico 1). Além da carga horária habitual de trabalho, 59 (26,1\%) afirmaram levar trabalho para casa pelo menos uma vez na semana, sendo que $15(6,64 \%)$ levam trabalho pelo menos três vezes por semana.

Gráfico 1 - Carga Horária Trabalhada durante a dupla jornada

\section{Carga Horária Trabalhada}

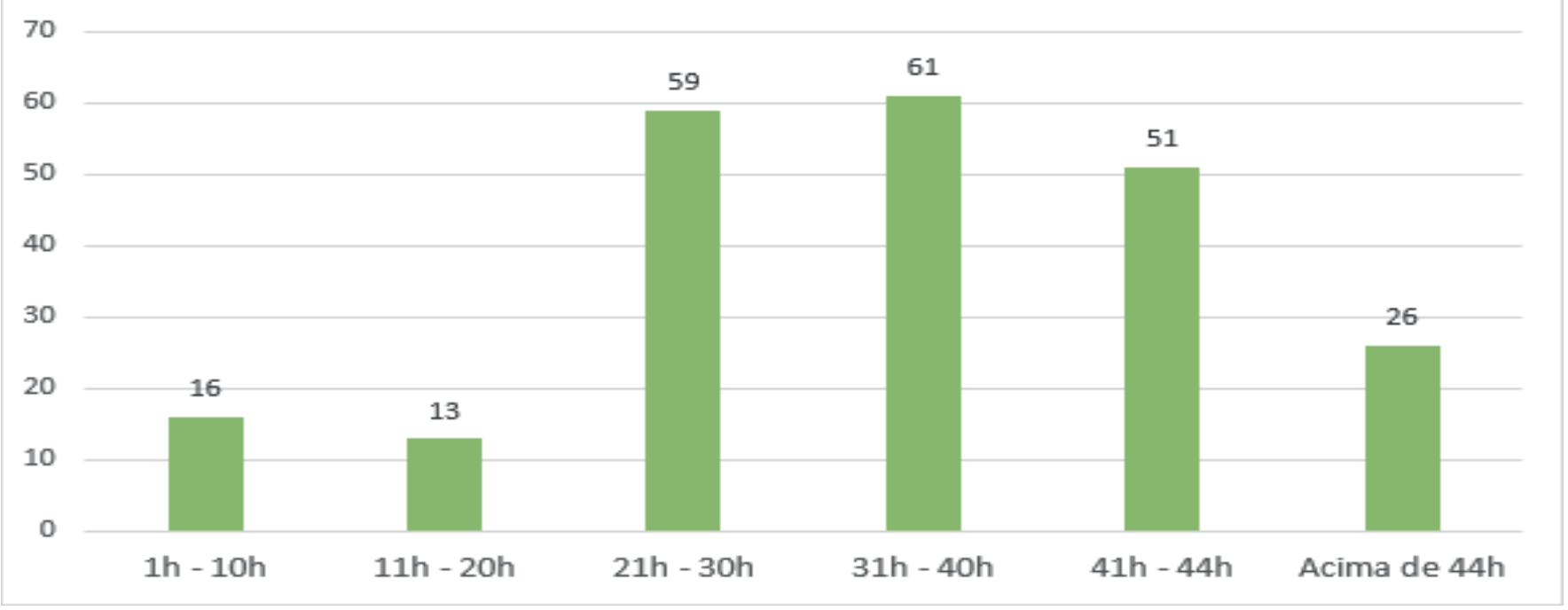

Fonte: dados da pesquisa

Nas respostas obtidas a partir da pergunta sobre qual meio de transporte utilizam para ir ao trabalho, 134 (59,3\%) afirmaram ir de metrô, trem ou ônibus, enquanto 64 (28,3\%) utilizam carro próprio e 11 (4,87\%) vão a pé. Já sobre o transporte para a faculdade, 130 (57,5\%) utilizam metrô, trem ou ônibus, 62 (27,4\%) utilizam carro próprio e 20 (8,85\%) vão a pé.

Para a afirmação "O fato de conciliar trabalho e estudo prejudica/prejudicava o meu desempenho na faculdade" 156 (69\%) respondentes concordaram totalmente ou parcialmente, 32 (14,2\%) discordaram totalmente ou parcialmente e 38 (16,8\%) não concordaram, nem discordaram. Já na afirmação sobre conciliar trabalho e faculdade prejudicar o desempenho no trabalho, $79(34,96 \%)$ concordaram totalmente ou parcialmente, 84 (37,2\%) discordaram totalmente ou parcialmente e $63(27,9 \%)$ não concordaram, nem discordaram (gráfico 2).

Gráfico 2 - Percepção sobre o impacto no desempenho ao conciliar trabalho e estudo

\section{Impactos no Desempenho na Faculdade}

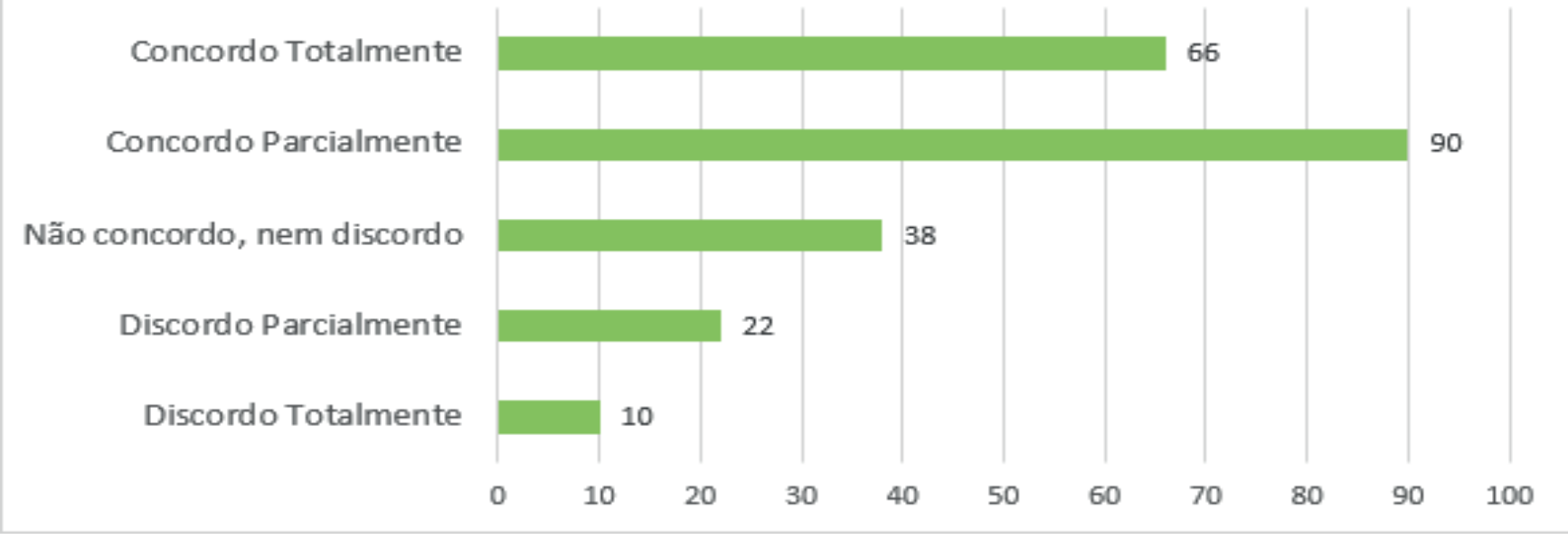

Fonte: dados da pesquisa

Revista ADMPG, Ponta Grossa, v. 10, e2014761, p. 1- 13, 2020. 


\subsection{Quanto a Satisfação no Trabalho}

Dos respondentes, 46 (20,4\%) concordam totalmente com a afirmação "Me sinto/sentia satisfeito(a) com o meu trabalho", enquanto 15 (6,6\%) discordam totalmente, 87 (38,5\%) concordam parcialmente, 21 (9,29\%) discordam parcialmente e 57 (25,2\%) não concordam, nem discordam. Além disso, 33 (14,6\%) concordam totalmente que sentem que a empresa se preocupa com o seu bem-estar, 33 (14,6\%) discordam totalmente, 49 (21,7\%) concordam parcialmente, 55 (24,3\%) discordam parcialmente e 56 (24,8\%) não concordam, nem discordam.

Dos respondentes, $57(25,2 \%)$ concordam totalmente ou parcialmente que a empresa se preocupa com seu desempenho na faculdade, enquanto 113 (50\%) discordam totalmente ou parcialmente, e 56 (24,8\%) não concordam, nem discordam. Além disso, 110 (48,7\%) pessoas concordam totalmente ou parcialmente com sentir que tem possibilidade de crescimento no trabalho, enquanto $68(30,1 \%)$ discordam totalmente ou parcialmente e 48 (21,2\%) não concordam, nem discordam.

Quando perguntados se sentiam que seus superiores reconhecem seu trabalho, 131 (58\%) concordam totalmente ou parcialmente, $41(18,1 \%)$ discordam totalmente ou parcialmentee $54(23,9 \%)$ não concordam, nem discordam.

Sobre espaço físico, 145 (64,2\%) concordam totalmente ou parcialmente que se sentem bem no ambiente de trabalho, 27 (12\%) concordam totalmente ou parcialmente e 54 (23,9\%) não concordam, nem discordam. Entretanto, avaliando o ambiente de trabalho em função da relação com colegas e superiores, 155 (68,6\%) concordam totalmente ou parcialmente, $21(9,3 \%)$ discordam totalmente ou parcialmente e $50(22,1 \%)$ não concordam, nem discordam.

Do total de respondentes da pesquisa, 108 (47,8\%) afirmam que concordam totalmente ou parcialmente estarem satisfeitos com o salário e benefícios que recebem, $57(25,2 \%)$ discordam totalmente ou parcialmente e61 (26,7\%) não concordam, nem discordam. Um número expressivo de respondentes $(69 \%)$ concorda totalmente ou parcialmente que se sentem desgastados pela pressão de ter que conciliar trabalho e faculdade. Apenas 13,3\% discordam totalmente ou parcialmente e 17,7\% não concordam, nem discordam.

Quanto às perguntas sobre benefícios e atividades que a empresa oferece que acreditam que melhore o bem-estar, obtivemos os seguintes dados: a maioria dos respondentes têm horário flexível (23,4\%) ou não têm nenhuma atividade (20,7\%), 13,4\% têm ginástica laboral, 10\% têm incentivo às atividades físicas, 9,5\% têm massagem, 7\% têm home office, 5,8\% têm short friday, 4,4\% têm atendimento psicológico, 3,9\% têm atendimento nutricional, 1,2\% têm lanches, 0,5\% têm happy hour e 0,2\% têm manicure. Já sobre benefícios, 24,7\% têm vale refeição, 23,6\% têm plano de saúde, 17,1\% têm plano odontológico, 12,7\% têm vale alimentação, 8,4\% têm bônus por desempenho ou PLR, 7,6\% têm desconto em medicamentos, 0,8\% têm vale transporte, $0,2 \%$ têm Gympass (desconto em academias), $0,2 \%$ têm seguro de vida, enquanto 4,8\% não têm nenhum benefício.

\subsection{Quanto a Qualidade de Vida no Trabalho - QVT}

Na pergunta sobre atividades que acreditam que a empresa poderia oferecer, a divisão fez-se da seguinte forma: $15,7 \%$ gostariam de ter home office, 14,6\% gostariam de ter atendimento psicológico, 13,9\% gostariam de ter horário flexível, 13,8\% gostariam de ter short friday, 13,2\% gostariam de ter massagem, 10,8\% gostariam de ter incentivo à atividades físicas, 8,8\% gostariam de ter ginástica laboral, 7,3\% gostariam de ter atendimento nutricional, $0,1 \%$ já possui home office, mas gostaria de ter mais vezes na semana, $0,4 \%$ responderam outras atividades (party time, sala de jogos e yoga) e 1,4\% acreditam que não precisam de mais nenhuma atividade. Sobre os benefícios, $22,1 \%$ sentem que poderiam ter bônus por desempenho, $16 \%$ gostariam de ter plano de saúde, 14,6\% gostariam de ter vale alimentação, 13,9\% gostariam de ter plano odontológico, 13,5\% gostariam de ter vale refeição, 10,3\% gostariam de ter desconto em medicamentos, $0,4 \%$ gostariam de ter bolsa de estudos e $0,8 \%$ gostariam de ter outros (Gympass, beneflex, vale gasolina/ estacionamento) e 8,4\% acreditam que não necessitam ter mais nenhum benefício além dos que já têm.

Quando perguntados sobre os sintomas que sentiram no momento em que tiveram que conciliar trabalho e faculdade, os respondentes puderam responder mais de um sintoma sentido, sendo que as opções foram colocadas de acordo com os sintomas da Síndrome de Burnout. A quantidade de respostas obtidas foi

Revista ADMPG, Ponta Grossa, v. 10, e2014761, p. 1- 13, 2020. 
dividida pelos sintomas, nos mostrando que $15,2 \%$ sentem cansaço constante, $12,1 \%$ sentem fadiga, $11,4 \%$ sentem alterações de humor, 10,7\% sentem dificuldade de concentração, 10,1\% sentem irritabilidade, 9,4\% sentem dor de cabeça, 8,8\% tem distúrbios do sono, $6 \%$ tem alterações de memória, 5,6\% sentem dores musculares, $5 \%$ sofrem perda de iniciativa, $4,1 \%$ sofrem de depressão, 1,4\% sofrem de falta de apetite e apenas uma pessoa (0,1\%) não sente/sentiu nenhum dos sintomas (gráfico 3).

Gráfico 3. Percepção de sintomas durante a dupla jornada (trabalho / universidade)

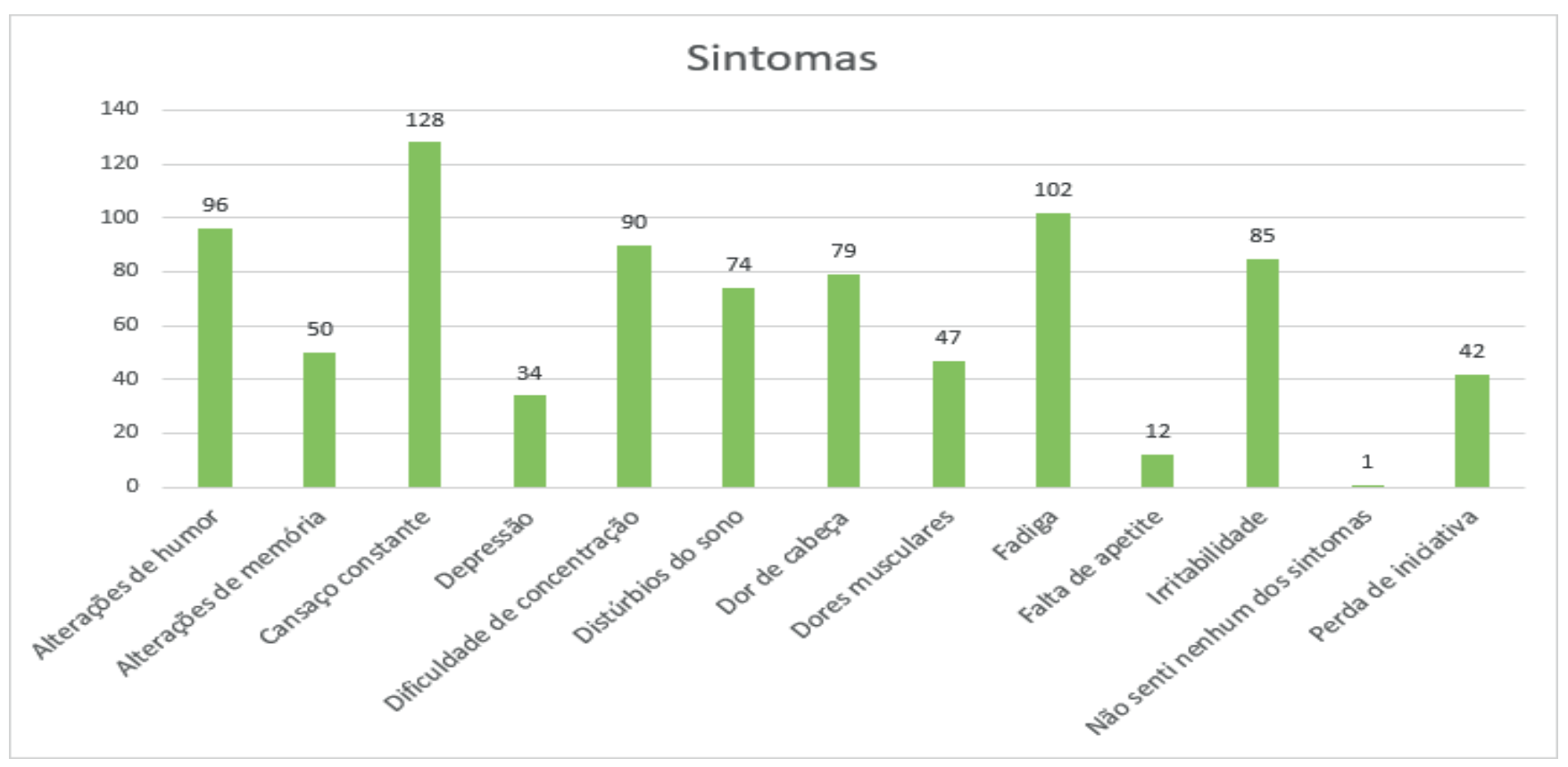

Fonte: dados da pesquisa

Por fim, na última pergunta, "Se eu tivesse escolha, só começaria a trabalhar depois que acabasse a faculdade", onde as respostas obtidas foram $112(49,6 \%)$ concordam totalmente ou parcialmente, 82 $(36,3 \%)$ discordam totalmente ou parcialmente e 32 (14,1\%) não concordam, nem discordam.

\subsection{Correlações na ANÁlise dos dados}

Para buscar analisar diferentes variáveis levantadas, foram realizados alguns testes estatísticos como ANOVA. Para entender se a relação entre o desempenho dos respondentes na faculdade é afetado pela conciliação entre trabalho e faculdade com o fato de que, se tivessem escolha, começariam a trabalhar apenas depois da faculdade, obteve-se um p-valor de 0,0000000652378, muito abaixo do alfa utilizado de 0,05 (tabela 1). Com esse resultado podemos observar que pode sim existir uma relação entre aqueles que acreditam que conciliar trabalho e faculdade afeta o desempenho universitário, com aqueles que, se pudessem, começariam a trabalhar apenas depois de formados.

Tabela 1. Correlação entre a percepção de Desempenho e a dupla jornada

Anova: factor único

SUMARIO

Grupos

\begin{tabular}{rrrrr} 
& Contagem & \multicolumn{1}{c}{ Soma } & \multicolumn{1}{c}{ Média } & Variância \\
\hline 1 & 10 & 16 & 1,6 & 0,71111111 \\
2 & 22 & 48 & 2,18181818 & 2,06060606 \\
3 & 38 & 106 & 2,78947368 & 2,0625889 \\
4 & 90 & 319 & 3,54444444 & 2,52047441 \\
5 & 66 & 257 & 3,89393939 & 2,18857809 \\
\hline
\end{tabular}

ANOVA

\begin{tabular}{|c|c|c|c|c|c|c|}
\hline $\begin{array}{l}\text { Fonte de } \\
\text { variaçẫo }\end{array}$ & SQ & $g i$ & $M Q$ & $F$ & vaior $P$ & F critico \\
\hline Entre grupos & 94,9715083 & 4 & 23,7428771 & 10,6526865 & $\begin{array}{r}6,52378 E- \\
08\end{array}$ & 2,4124959 \\
\hline Dentro de grupos & 492,568315 & 221 & 2,2288159 & & & \\
\hline Total & 587,539823 & 225 & & & & \\
\hline
\end{tabular}

Fonte: dados da pesquisa

Revista ADMPG, Ponta Grossa, v. 10, e2014761, p. 1- 13, 2020. 
No teste ANOVA para relacionar aqueles que levam/levavam trabalho para casa com frequência, com conciliar trabalho e estudo prejudicam o desempenho na faculdade (tabela 2), obteve-se um p-valor de 0,015298, ou seja, menor que o alfa 0,05. Sendo assim, a hipótese nula foi rejeitada, mostrando indícios de que pode haver relação entre a quantidade de vezes que o estudante leva/levava trabalho para casa com acreditar que conciliar estudo e trabalho afetava o desempenho na faculdade. Entretanto, não se pode afirmar que com certeza exista essa relação, ou o motivo dela existir. Para investigar se isso de fato acontece e o porquê, seria necessário utilizar uma amostra maior.

Tabela 2. Correlação entre Desempenho na faculdade e excesso de trabalho

Anova: fator único

RESUMO

\begin{tabular}{lrrrr}
\hline \multicolumn{1}{c}{ Grupo } & Contagem & Soma & \multicolumn{1}{c}{ Média } & Variância \\
\hline Não costumo/costumava levar trabalho para casa & 167 & 617 & 3,694611 & 1,17726 \\
Uma vez por semana & 15 & 64 & 4,266667 & 0,92381 \\
Duas vezes por semana & 17 & 69 & 4,058824 & 1,058824 \\
Très vezes por semana & 12 & 41 & 3,416667 & 2,44697 \\
Mais de três vezes por semana & 15 & 67 & 4,466667 & 0,409524 \\
\hline
\end{tabular}

\begin{tabular}{|c|c|c|c|c|c|c|}
\hline Fonte da variaçāo & $S Q$ & $g !$ & $M Q$ & $F$ & valor-P & Fcritico \\
\hline Entregrupos & 14,68751 & 4 & 3,671877 & 3,145904 & 0,015298 & 2,412496 \\
\hline Dentro dos grupos & 257,9497 & 221 & 1,167193 & & & \\
\hline Total & 272,6372 & 225 & & & & \\
\hline
\end{tabular}

Fonte: dados da pesquisa

Para entender a relação entre a carga horária semanal cumprida pelos respondentes com a opinião sobre conciliar trabalho e estudo prejudicar o desempenho na faculdade (tabela 3), foi utilizado novamente $o$ teste ANOVA com alfa de 0,05. Obteve-se um p-valor maior que alfa, 0,749965, confirmando, novamente, a hipótese nula de que a percepção de respondentes com diferentes cargas horárias semanais com relação ao desempenho na faculdade não altera significativamente de acordo com a carga horária. As médias variaram de 3,677966, com variância de 1,084161, para pessoas com carga horária semanal de 2lh-30h, a 4, com variância de 1,44, para pessoas com carga horária semanal acima de 44h.

Tabela 3. Correlação entre o desempenho na faculdade e carga horário no trabalho

Anova: fator único

\begin{tabular}{lrrrr}
\multicolumn{1}{c}{ RESUMO } & Contagem & \multicolumn{1}{c}{ Soma } & Média & Variância \\
\hline $1 \mathrm{~h}-10 \mathrm{~h}$ & 16 & 59 & 3,6875 & 1,1625 \\
$11 \mathrm{~h}-20 \mathrm{~h}$ & 13 & 48 & 3,692308 & 1,230769 \\
$21 \mathrm{~h}-30 \mathrm{~h}$ & 59 & 217 & 3,677966 & 1,084161 \\
$31 \mathrm{~h}-40 \mathrm{~h}$ & 61 & 239 & 3,918033 & 1,043169 \\
$41 \mathrm{~h}-44 \mathrm{~h}$ & 51 & 191 & 3,745098 & 1,513725 \\
Acima de 44h & 26 & 104 & 4 & 1,44 \\
\hline
\end{tabular}

\begin{tabular}{lcrrrrr} 
ANOVA & \multicolumn{1}{c}{ SQ } & gf & MQ & \multicolumn{1}{c}{ F } & valor-P & Fcrítico \\
\hline Fonte da variação & \multicolumn{1}{c}{ Son } & & \\
\hline Entre grupos & 3,272643 & & 0,654529 & 0,534578 & 0,749965 & 2,255094 \\
Dentro dos grupos & 269,3645 & 220 & 1,224384 & & & \\
& & & & & & \\
Total & 272,6372 & 225 & & & & \\
\hline
\end{tabular}

Fonte: dados da pesquisa

Revista ADMPG, Ponta Grossa, v. 10, e2014761, p. 1- 13, 2020. 
Tabela 4. Correlação sobre a percepção de qualidade de vida no Trabalho

Anova: factor único

SUMÁRIO

\begin{tabular}{lrrrc}
\hline \multicolumn{1}{c}{ Grupos } & Contagem & \multicolumn{1}{c}{ Soma } & \multicolumn{1}{c}{ Média } & Variância \\
\hline Discordam Totalmente & 50 & 159 & 3,18 & 1,70163265 \\
Discordam Parcialmente & 32 & 95 & 2,96875 & 1,64415323 \\
Não Concordam nem Discordam & 32 & 97 & 3,03125 & 1,12802419 \\
Concordam Parcialmente & 24 & 80 & 3,33333333 & 1,36231884 \\
Concordam Totalmente & 88 & 241 & 2,73863636 & 1,80446708 \\
\hline
\end{tabular}

ANOVA

\begin{tabular}{|c|c|c|c|c|c|c|}
\hline Fonte de variação & $S Q$ & $g l$ & $M Q$ & $F$ & valor $P$ & Fcritico \\
\hline Entregrupos & 10,2012383 & 4 & 2,55030957 & 1,57594019 & 0,18168477 & 2,4124959 \\
\hline Dentro de grupos & 357,63947 & 221 & 1,61827814 & & & \\
\hline Total & 367,840708 & 225 & & & & \\
\hline
\end{tabular}

Fonte: dados da pesquisa

Ao relacionar a questão de apenas começar a trabalhar depois de formados, com se a empresa se preocupa com seu bem-estar, também foi utilizado ANOVA (tabela 4). Chegou-se em um p-valor $(0,18168477)$ maior que o alfa utilizado $(0,05)$, mais uma vez mostrando que não há evidências de que exista uma correlação entreos dois fatores. O mesmo aconteceu com o teste ao relacionar curso degraduação(p-valor 0,31874008), departamento em que trabalhavam (p-valor 0,34307011), segmento da empresa (p-valor 0,37707584) e gênero (p-valor 0,28056722) com o sentimento de que a empresa se importa com o bem-estar.

\section{DISCUSSÃO DOS RESULTADOS}

De acordo com Limongi-França, Limongi-França e Barbosa (2016), as primeiras ações a serem tomadas para melhorar a QVT, são aquelas que recuperem a saúde daqueles que já estão doentes. A presente pesquisa verificou que atividades como atendimento psicológico e nutricional estão presentes em apenas 8,3\% das empresas dos entrevistados, enquanto 21,9\% dos indivíduos afirmam que são atividades que gostariam que suas empresas oferecessem para melhorar a QVT. Após as ações de contenção, devem ser tomadas as ações de prevenção. Pelos respondentes, atividades como ginástica laboral, home office, happy hour, short friday e massagem estão presentes em 36,3\% das empresas, enquanto 51,6\% dos indivíduos gostariam de ter e acreditam que tais atividades melhorariam sua QVT.

Em relação aos sintomas que podem evidenciar a exaustão emocional (Lírio, Severo \& Guimarães, 2018), dentre eles, alterações de humor, alterações de memória, cansaço constante, depressão, dificuldade de concentração, distúrbios do sono, dor de cabeça, dores musculares, fadiga, falta de apetite, irritabilidade e perda de iniciativa. Obteve-se apenas $1(0,1 \%)$ indivíduo que afirmou não sentir nenhum dos sintomas enquanto teve que conciliar trabalho e estudos.

Ainda de acordo com Boas \& Morin (2017) o desgaste no ambiente de trabalho deriva dos seguintes fatores: "excesso de trabalho, falta de controle, remuneração insuficiente, colapso da união, ausência de equidade e valores conflitantes”. Para avaliar tais condições, foram realizadas algumas perguntas sobre satisfação com salário e benefícios recebidos, satisfação com o trabalho, carga horária semanal, relação com colegas e superiores, sentimento de trabalho reconhecimento, de possibilidades de crescimento dentro da empresa e preocupação da empresa com bem-estar e desempenho na faculdade. De maneira geral, obteve-se mais

Revista ADMPG, Ponta Grossa,v. 10, e2014761, p. 1- 13, 2020. 
respostas positivas sobre essas questões do que negativas, mostrando que a maioria está satisfeita com pacote de remuneração, relações interpessoais e preocupação da empresa com suas questões pessoais, corroborando com achados também da pesquisa de Santos e Borges (2018).

Conforme sinalizado por Freudenberger e Richelson (1991), indivíduos que trabalham com atividades que demandam muita energia, esforço, ou que não condizem com o que a pessoa acredita, têm propensão a desenvolver a Síndrome de Burnout. Com base na quantidade de sintomas que os respondentes afirmaram ter apresentado durante o período em que tiveram que conciliar a dupla jornada, é provável que o desgaste prolongado possa ter caminhado para o desenvolvimento de Burnout. Entretanto, uma análise mais aprofundada se faz necessária para avaliar outros fatores das vidas dos indivíduos que apresentaram os sintomas que podem ser correlacionados com a síndrome, assim como o diagnóstico por um profissional da área da saúde.

\section{CONSIDERAÇÕES FINAIS}

Com base nos resultados apresentados, é possível verificar que há evidências empíricas e estatísticas que a dupla jornada de estudantes que conciliaram vida acadêmica e profissional tem impactos na QVT. Além disso, se considerarmos questões de modo isolado, há uma porcentagem significativa de indivíduos que afirmam que conciliar estudo e trabalho ao mesmo tempo tem impactos no desempenho no trabalho e nos estudos.

De acordo com a percepção dos respondentes, 47,79\%, as empresas nas quais atuaram, no momento em que tiveram que conciliar trabalho e estudo, oferecem benefícios e remuneração satisfatória. Além disso, os respondentes sinalizaram que recebem benefícios diferenciados, demostrando que há indícios de que grande parte das empresas se preocupa com a QVT e que acabam por impactar de alguma forma como os estudantes conciliam a vida profissional com a acadêmica. Porém, um número expressivo de profissionais, 85 (37,61\%), sinalizou que a empresa não oferece nenhum tipo de atividade voltada para a melhoria da QVT. Isso indica a oportunidade de que as empresas, nas quais esses indivíduos trabalharam, analisem a possibilidade de implantação de atividades voltadas à QVT como forma de prevenir ou diminuir os impactos da pressão e estresse das atividades diárias. Levando em consideração as atividades desejáveis com maior número de sinalizações na pesquisa, pode-se citar short friday, home office e horário flexível.

\subsection{Implicações Práticas}

O presente trabalho demonstra-se importante para que as Instituições de Ensino e, principalmente, as empresas, possam avaliar melhor como lidam com aqueles indivíduos que realizam a dupla jornada de estudo e trabalho. Analisando isoladamente uma das questões abordadas, existe um forte indício de que esses indivíduos não estão satisfeitos, pois quase $40 \%$ afirmou que, se tivesse escolha, começaria a trabalhar apenas depois de formados e 10,62\% concordam parcialmente com essa afirmação, contra $36,28 \%$ que discordam totalmente ou parcialmente.

Além disso, os sintomas relatados pelos indivíduos quando tiveram que trabalhar e estudar ao mesmo tempo também demonstram o impacto que a dupla jornada pode causar na vida dos estudantes, uma vez que se obteve respostas como cansaço constante em 15,2\% dos indivíduos, fadiga em 12,1\% e depressão em $4 \%$, por exemplo.

É importante destacar também que apenas 25\% concordam totalmente ou parcialmente que a empresa se preocupa com o desempenho na faculdade, enquanto $50 \%$ discordam totalmente ou parcialmente. Mostrando, assim, que são poucas as empresas que se preocupam em garantir que seus funcionários tenham um bom desempenho na faculdade, mesmo que isso possa implicar, no futuro, no próprio desempenho dos funcionários na empresa.

\subsection{Limitações da Pesquisa e Pesquisas Futuras}

Levando em consideração que a amostra obtida pela pesquisa é composta por indivíduos que já se formaram há anos e também por indivíduos que ainda estão cursando a graduação, é possível que

Revista ADMPG, Ponta Grossa, v. 10, e2014761, p. 1- 13, 2020. 
a percepção sobre os impactos da dupla jornada e sobre os sintomas relatados tenha sido atenuada, uma vez que os respondentes que se graduaram há mais tempo podem apresentar falta de precisão nas respostas. Além disso, fatores limitantes para a análise dos dados e conclusões, podem ter sido o tamanho da amostra, pois com uma amostragem maior, testes estatísticos mais robustos poderiam ter sido utilizados, e sua homogeneidade, uma vez que a grande maioria dos respondentes foram jovens de uma grande capital.

Por essas razões, entende-se que estudos futuros, ao realizarem pesquisas com amostras mais específicas, podem se aprofundar ainda mais nas consequências que a falta da QVT pode ter sobre o desempenho de estudantes tanto na faculdade, quanto no trabalho. Além disso, podem também analisar mais precisamente as razões pelas quais as evidências sugerem que há relação entre o desempenho na faculdade com escolher começar a trabalhar apenas depois de formados e com levar trabalho para casa, bem como analisar se não há indícios de que exista algum tipo de correlação entre outros fatores que tenham ligação com a QVT.

\section{REFERÊNCIAS}

Boas, A. A. V.; Morin, E. (2017) Qualidade de Vida no Trabalho: Um Modelo Sistêmico de Análise. Revista Administração em Diálogo, v. 19, n. 2, p. 62-90.

Cardoso, Wilma Lucia C. D.; Guimarães, Liliana A. M. (2004) Atualizações sobre a síndrome de Burnout. São Paulo: Casa do psicólogo.

Castro, Fernando Gastal De. (2013) Burnout e a Complexidade Histórica. Revista Psicologia: Organizações e Trabalho, Rio de Janeiro, RJ, v. 13, n. 1, p. 49-59, jan.

Collis, Jill; Hussey, Roger. (2005). Pesquisa em Administração: Um guia prático para alunos de graduação e pós-graduação. 2. ed. São Paulo: Bookman Companhia Editora, 339 p.

Coutinho, M. L. G.; Maximiano, A. C. A.; Limongi-França, A. C. (2010). Implantação de Programas de Qualidade de Vida no Trabalho com o modelo de gestão de projetos. Revista de Gestão e Projetos, v. 1, n. 1, p. 172-189.

Dejours, C.; Dessors, D.; Destriaux, F. (1993). Por um trabalho, fator de equilíbrio. Tradução de Maria Irene S. Bertiol. São Paulo: ERA.

Hair, Joseph F. (2005) Fundamentos de métodos de pesquisa em administração. Porto Alegre: Bookman, $471 \mathrm{p}$.

Kanikadan, A. Y. S.; Limongi-França, A. C. A (2007). Qualidade de Vida no Trabalho dos professores de inglês. Revista Brasileira de Gestão de Negócios, v. 9, n. 25, p. 59-80, 2007.

Kurogi, M.S. (2008). Qualidade De Vida No Trabalho E Suas Diversas Abordagens. Revista de Ciências Gerenciais, São Paulo, v. XII, n. 16, p. 49-62.

Limongi-França, A C. 1997. Qualidade de vida no trabalho: Conceitos, abordagens, inovações e desafios nas empresas brasileiras, Revista Brasileira de Medicina Psicossomática. Rio de Janeiro, vol. 1, n o2, p.7983.

Limongi-França, A C. Limongi-França, A C. Barbosa, Carla. (2016). Revista InterAtividade: Qualidade de vida no Trabalho. $1^{\circ}$. ed. Andradina: Faculdades Integradas "Rui Barbosa" - FIRB, 11 p. v. $1^{\circ}$.

Limongi-França, A C. (2008) .Psicologia do trabalho: psicossomática, valores e práticas organizacionais. São Paulo: Saraiva.

Lírio, A. B.; Severo, E. A.; Guimarães, J. C. F. A (2018). Influência da Qualidade de Vida no Trabalho sobre o Comprometimento Organizacional. Revista Gestão \& Planejamento, v. 19, n. 1, p. 34-54.

Marras, Jean Pierre. (2010). Gestão estratégica de pessoas: Conceitos e tendências. $1^{\circ}$. ed. São Paulo: Saraiva, 357p.

Revista ADMPG, Ponta Grossa, v. 10, e2014761, p. 1- 13, 2020. 
Mattar, F. Pesquisa de marketing. Ed. Atlas. 1996

Pereira, Ana Maria T. B. (2002). Burnout: quando o trabalho ameaça o bem-estar do trabalhador. 1. ed. São Paulo: Casa do Psicólogo, 282 p.

Santos, P. S. D.; Borges, G. R. (2018) A Influência da Satisfação e Qualidade de Vida no Trabalho entre Alunos do Curso de Agronegócio. Revista de Carreiras e Pessoas, v. 8, n. 3, p. 375-397.

Trigo, T.R; Teng, C.T.; Hallak, J.E.C. (2007). Síndrome de burnout ou estafa profissional e os transtornos psiquiátricos. Revista de psiquiatria Clínica, v. 34, n. 5, p. 223-233.

Zanelli, José Carlos et al. (Org.). (2010) Estresse nas Organizações de Trabalho: Compreensão e Intervenção Baseadas em Evidências. Porto Alegre: Artmed, 128 p.

recebido em: $12 / 2019$

aceito em: 03/2020

publicado em: 04/2020 